Vol. 1, No. 2, pp. 125-136, (December 2020)

DOI: 10.21608 /aujes.2020.127561

Aswan University Journal of Environmental Studies (AUJES)

Online ISSN: 2735-4237, Print ISSN: 2735-4229

Journal homepage: https://aujes.journals.ekb.eg/

Original research

\title{
Magnesium Sorption onto Titan Yellow Supported on Classic Thiourea- Formaldehyde Resin
}

\author{
Khalid Z. Elwakeel \\ University of Jeddah, College of Science, Department of Chemistry, Jeddah, Saudi Arabia \\ Environmental Science Department, Faculty of Science, Port-Said University, Port-Said, Egypt
}

Received: $22 / 8 / 2020$

Accepted: 19/10/2020

(C) Unit of Environmental Studies and Development, Aswan University

\begin{abstract}
:
Magnesium is a common water hardness source. This divalent ion can react with soap anions that reduce cleaning efficiency, resulting in high detergent consumption. The development of new low-cost metal removal adsorbents has attracted a great deal of attention. Here the adsorption behavior and the underlying kinetics of magnesium sorption on Titan yellow (TY) supported on thiourea-formaldehyde resin (TF) was investigated. The results of analyzing sorption behavior showed that the sorption environment had different effects on the sorption of $\mathrm{Mg}$ (II) ions. It could be found that the initial $\mathrm{pH}$ had the best sorption effect on $\mathrm{Mg}$ (II) ions, the equilibrium is reached within 115-120 min and the kinetic profiles are simulated by the pseudosecond-order rate equation (PSORE). The maximum adsorption capacity of $\mathrm{Mg}$ was $19.45 \mathrm{mg} \mathrm{g}^{-1}$ at initial $\mathrm{pH}=10.5$. Under the optimal conditions, the maximum sorption capacity of $\mathrm{Mg}$ (II) ions reaches up to $19.45 \mathrm{mg} \mathrm{g}^{-1}$. Therefore, TF-TY was found to be an efficient adsorbent for $\mathrm{Mg}$ (II) removal from water.
\end{abstract}

Keywords: Adsorption; $\mathrm{Mg}(\mathrm{II})$ ions; Titan yellow; Kinetic.

\section{1- INTRODUCTION}

People cannot live without water. Water is the source of life and an important component of sustainable economic and social development. The need for drinking water quality standards require continuous upgrading of water purification technology. Presence of hardness ions in the municipal drinking water is the major health concern. Water hardness can be attributed to the presence of certain ions in water which can easily form undissolved salts (Pilehvar et al., 2020). Some of the common ions include calcium ions, magnesium ions, ferrous ions, manganese ions and aluminum ions. Treatment processes often include the removal of these ions due to certain water quality requirements (El-Nahas et al., 2020). So to minimize the hardness of drinking water up to the Environmental Protection Authority (EPA) quality standard, expensive treatments are required. However, in actual water bodies, cationic hardness substances are often widespread. Less than one percent of fresh water is accessible from ground level for human consumption (Harper and Snowden, 2017).

Corresponding authors*: E-mail addresses: kelwkeel@uj.edu.sa; khalid_elwakeel@sci.psu.edu.eg 
In some cases, the resource does not satisfy to the desirable levels regarding their chemical composition, such as hardness, nitrate contamination, heavy metals, soluble iron, etc (Abukhadra et al., 2020; Hailu et al., 2019). From that undesirable chemicals that most groundwater sources have; water hardness is the dominant one and major challenge for most of the water supply systems (Xu et al., 2020). In general, water supplies with total hardness higher than $200 \mathrm{mg} \mathrm{L}^{-1}$ can be tolerated, but considered to be poor resources; while values higher than $300 \mathrm{mg} \mathrm{L}^{-1}$ are not acceptable for most of the domestic consumptions (Patil et al., 2020). An existence of the calcium, magnesium and carbonate ions on the earth layer influences the hydrochemistry of groundwater (Avci et al., 2018). Hardness of water is due to moisture and carbon dioxide reacts with calcium and magnesium ion present on the earth surface (Hailu et al., 2019). The type of hardness has been categories in temporary and permanent; temporary hardness can be reduced by boiling, but permanent hardness required specific treatment (Ojha, 2020). Drinking highly hard water for a long time can cause cardiovascular, nervous, urinary and hematopoietic diseases (Comstock and Boyer, 2014; Ndii et al., 2020). Therefore, it is necessary to carry out studies develop a new method for removal of water hardness. Water treatment methods mainly include coagulation and flocculation, precipitation, chemical oxidation and membrane separation (Saleh et al., 2020). Such techniques suffer from high cost, low efficiency and a large number of by-products (Alaei Shahmirzadi et al., 2018; Burn et al., 2015). By contrast, adsorption technique, due to simplicity and low cost, attracted many attentions as an efficient method for desalination processesadsorption technology is widely used because of its easy handling, low cost and high efficiency (Shahmirzadi et al., 2016). Adsorption is considered as a valid method for balanced separation and water purification applications (Elwakeel et al., 2020a).

In recent years, domestic and foreign scholars have begun to look for new efficient and cheap adsorbent materials for magnesium sorption. This paper intended to use as a new material to study the adsorption behavior of $\mathrm{Mg}$ (II) ions. Firstly, the factors affecting the adsorption effect were investigated, and then the adsorption process was optimized by analyzing various parameters of adsorption kinetics. The purpose of this study was to explore the adsorption efficiency and kinetics of $\mathrm{Mg}(\mathrm{II})$ adsorption onto TF-TY adsorbent.

\section{2- MATERIALS AND METHODS}

\subsection{Chemicals}

Thiourea, formaldehyde solution (solution $37 \% \mathrm{w} / \mathrm{w}$ ), Ferric chloride and ferrous sulphate were supplied by Sigma-Aldrich (Germany) as analytical grade reagents. Titan yellow (Thiazole Yellow G) was supplied from Lobal Chemie (India).

\subsection{Preparation of the sorbent}

$15.2 \mathrm{~g}(0.2 \mathrm{~mol})$ of thiourea and $40 \mathrm{~mL}$ of distilled water were mixed in a $250 \mathrm{~mL}$ round flask equipped with a stirrer and condenser. The solution was heated until completed dissolution of thiourea. Then, $0.2 \mathrm{~mol}$ of formaldehyde ( $15 \mathrm{~mL}$ of $37 \%$ aqueous solution) was added to the flask, $\mathrm{pH}$ adjustment was made by using $2 \mathrm{~mL}$ of glacial acetic acid. The reaction was continued for approximately $4 \mathrm{~h}$ with heating $(368 \mathrm{~K})$ and stirring. The obtained white product was washed with ultrapure water from a Milli-Q system (Millipore, Billerica, MA). The produced polymer was dried for $600 \mathrm{~min}$ at $323 \mathrm{~K}$ and denoted as TF.

\section{Titan yellow loading procedure}

Known amounts of dry TF beads were put in contact with known amounts (volumeconcentration) of TY dye at $\mathrm{pH} 3$ at $25{ }^{\circ} \mathrm{C}$ for $3 \mathrm{~h}$. Later on, the residual concentration of TY 
was measured by using a uv-vis spectrophotometer (T70+ UV/VIS spectrophotometer, PG instruments Ltd, UK) at maximum wavelengths of TY (400 nm). The detailed adsorption characteristics of TY onto TF polymer was previously investigated in detail (Elwakeel et al., 2020b).

\subsection{Batch sorption experiment}

Batch adsorption studies were conducted by adding equal amounts of TF-TY ( $0.05 \mathrm{~g})$ to a series of identical plastic bottles equipped with $20 \mathrm{~mL} \mathrm{Mg(II)}$ ions solutions (20-200 $\mathrm{mg} \mathrm{L}^{-1}$ ) under a shaking incubator (LSI-3016R), at a certain temperature (298 K) to achieve equilibrium of the solution for $24 \mathrm{~h}$, then shaken at $150 \mathrm{rpm}$. The sample was extracted from the solution at appropriate intervals. The solution obtained by filtering through a filter paper (Whatman, diam. $47 \mathrm{~mm}$ ). The equilibrium adsorption capacity of $\mathrm{Mg}(\mathrm{II})$ and the removal efficiency of $\mathrm{Mg}(\mathrm{II})$ on TF-TY were obtained by the following equations, respectively.

$$
q_{e}=\frac{\left(C_{0}-C_{e}\right) \times V}{m}
$$

Where $\mathrm{C}_{0}$ and $\mathrm{C}_{\mathrm{e}}\left(\mathrm{mg} \mathrm{L}^{-1}\right)$ are the concentrations of $\mathrm{Mg}(\mathrm{II})$ in the liquid phase at initial and equilibrium, respectively. $\mathrm{V}(\mathrm{L})$ is the volume of the solution and $\mathrm{m}(\mathrm{g})$ is the mass of adsorbent used.

\subsection{Effect of solution $\mathrm{pH}$}

The effect of $\mathrm{pH}$ on adsorption was studied by adsorption studies under different $\mathrm{pH}$ conditions. The initial concentration of $20 \mathrm{~mL} \mathrm{Mg(II)} \mathrm{solution} \mathrm{was} \mathrm{set} \mathrm{to} 20 \mathrm{mg} \mathrm{L}^{-1}$, adjusted to different $\mathrm{pH}$ values ( $\mathrm{pH} 2-11$ ), and $0.05 \mathrm{~g}$ of TF-TY was added. The $\mathrm{pH}$ was measured by using a $\mathrm{pH}$ meter (HANNA 211, China). Then, it was placed in a constant temperature shaking incubator and temperature was controlled. After shaking for $24 \mathrm{~h}$, the sample was taken out and the amount of adsorption at this time was measured.

\subsection{Kinetics studies}

For kinetic experiments, $100 \mathrm{~mL} \mathrm{Mg(II)} \mathrm{solutions} \mathrm{of} 20 \mathrm{mg} \mathrm{L}^{-1}$ initial concentration was shaken for different time intervals with $0.1 \mathrm{~g}$ of TF-TY sorbent, and then the samples were taken and analyzed. Different kinetic models were used to study the rate control mechanism of $\mathrm{Mg}(\mathrm{II})$ ions adsorption onto TF-TY.

\section{3- RESULTS AND DISCUSSIONS}

\section{1- Characterization of TF-TY}

The FTIR spectra of TF-TY were listed in Fig. 1. The FTIR spectra obtained showed the functional groups of TF-TY. The peaks could be explained as follows: 3315 strong absorption peak indicates the presence of N-H of secondary amino group; $1625 \mathrm{~cm}^{-1}$ and 1156 are the distinguished peaks of $\mathrm{C}=\mathrm{S}-\mathrm{N}$ - bond of thiourea moiety; $1551 \mathrm{~cm}^{-1}$ is $\mathrm{C}=\mathrm{NH}$ peak; 1425 $\mathrm{cm}^{-1}$ and 1330 are the peaks of $\mathrm{C}-\mathrm{N} ; 960 \mathrm{~cm}^{-1}$ confirmed the presence of thioether bonds S-C.

Figure 2 shows some SEM micrographs of sorbent particles. The general structure of TF-TY adsorbents can be described as platelet agglomerated particles (layered material) with irregular objects of different sizes. Figure 3 shows the EDX spectra of TF-TY adsorbent: nitrogen and sulfur elements are clearly identified in the adsorbent material, while some impurities $(\mathrm{Cu}$ and $\mathrm{Zn})$ are appearing in TF-TY material which is sorbed from the dye solution. 


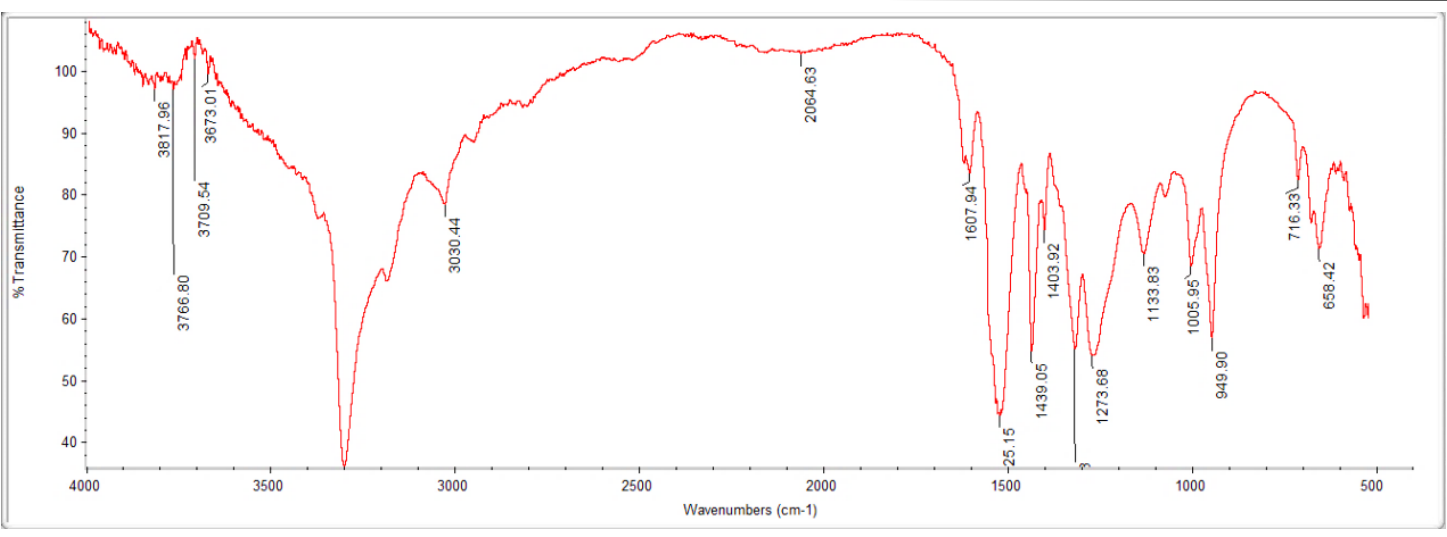

Fig. 1. FTIR spectra of TF-TY.
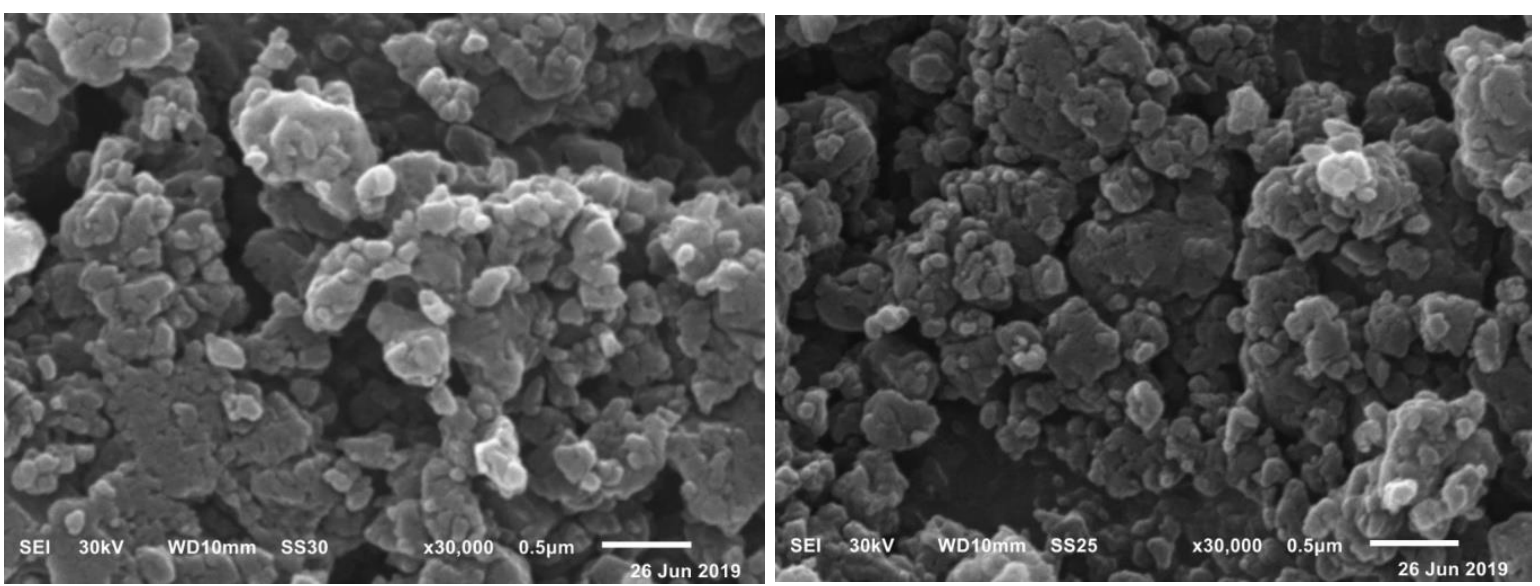

Fig. 2. SEM micrograph of TF-TY.

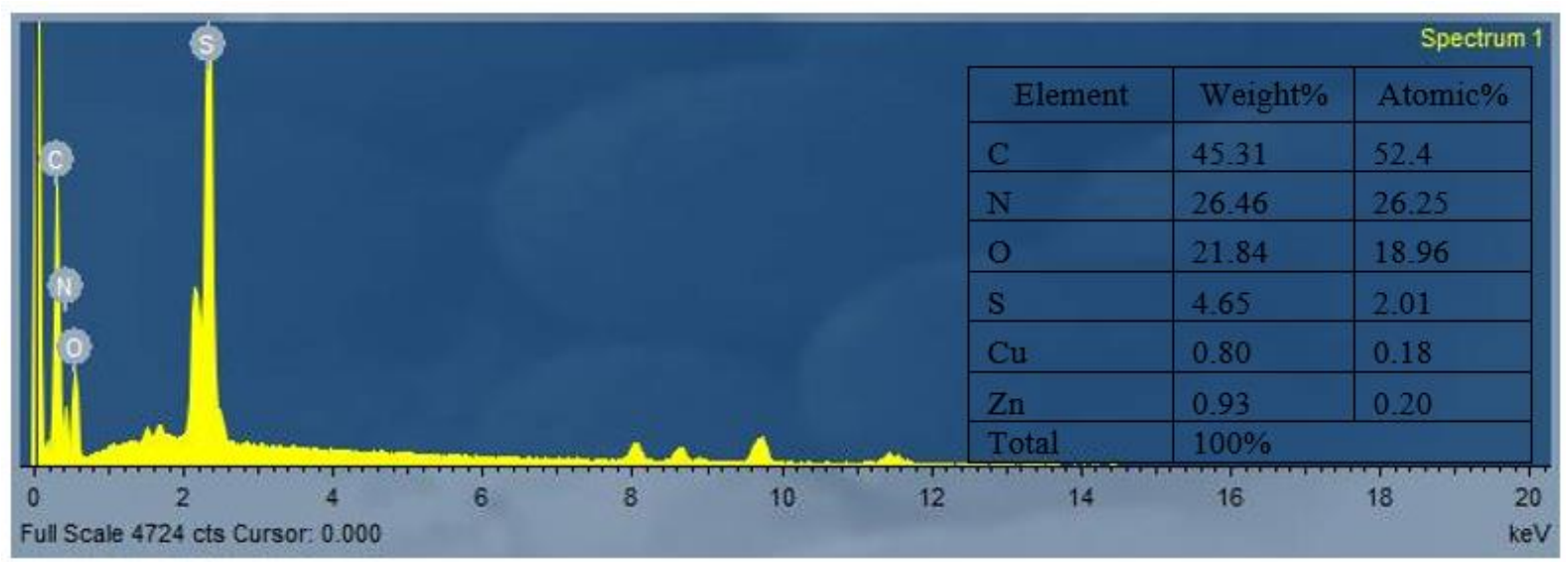

Fig. 3. EDX analysis of TF-TY adsorbent.

\section{2- Effect of pH}

The effect of the $\mathrm{pH}$ of the medium on the uptake was studied and the results are shown in Fig. 4. The highest uptake values were recorded at slightly alkaline $\mathrm{pH}$ of the $\mathrm{Mg}$ (II) ion solution. This may be attributed to the presence of free lone pair of electrons on nitrogen atoms as well as the presence of $-\mathrm{SO}_{3}{ }^{-}$groups suitable for coordination with $\mathrm{Mg}$ (II) ions to give the corresponding resin-metal complex. 


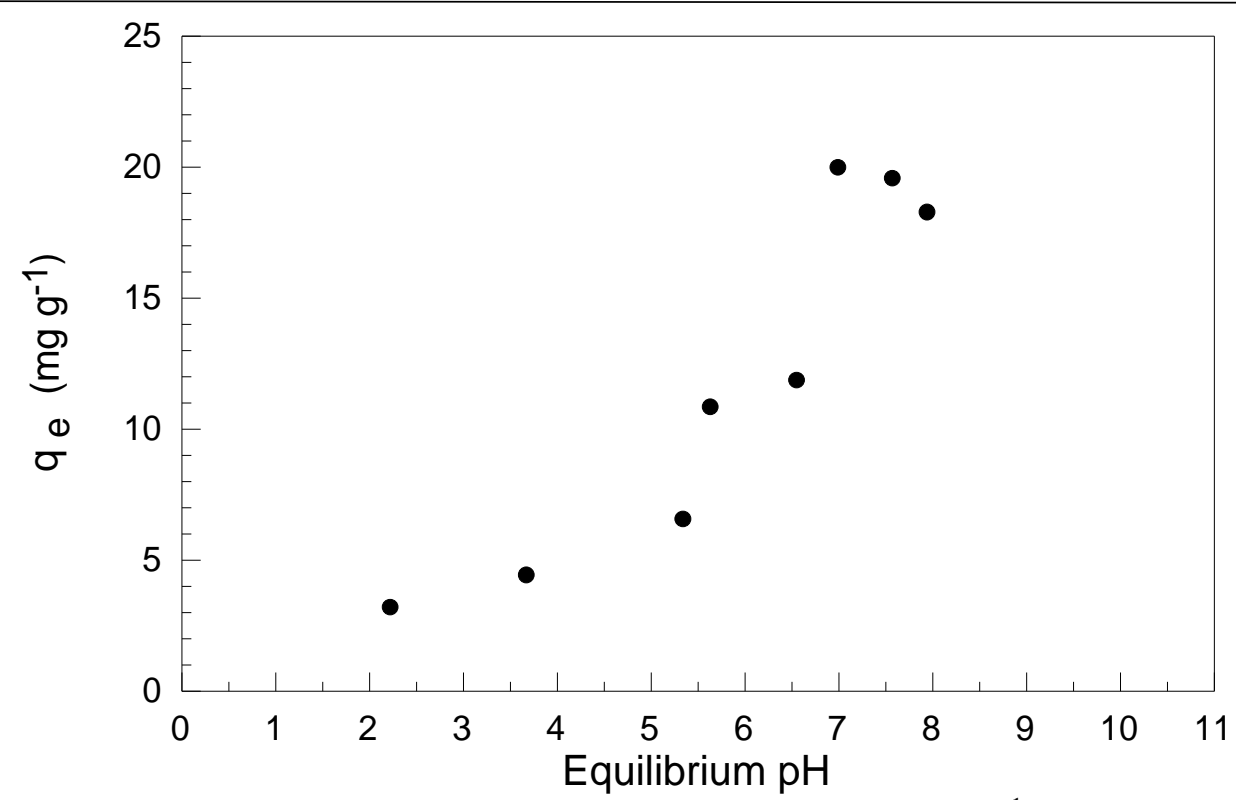

Fig. 4. Effect of $\mathrm{pH}$ on $\mathrm{Mg}$ (II) sorption by TF-TY ( $\mathrm{T}=298 \mathrm{~K}, \mathrm{C}_{0}=20 \mathrm{mg} \mathrm{L}^{-1}, \mathrm{~m}=0.05 \mathrm{~g}, \mathrm{~V}=20 \mathrm{~mL}$ ).

\section{3- Effects of contact time}

The effects of contact time on the adsorption of $\mathrm{Mg}$ (II) ions by TF-TY were studied. It could be seen from Fig. 5 that the adsorbed amount of $\mathrm{Mg}(\mathrm{II})$ by TF-TY increased with time. The adsorption results of the TF-TY showed that the amount of $\mathrm{Mg}$ (II) ions adsorbed to TF-TY increased rapidly with time at the beginning of the reaction, and then the amount of adsorption changed slowly and gradually stabilized. It was because there were a large number of empty positions on the surface of the TF-TY for adsorption in the initial stage, and when the reaction was in process, the remaining empty surface position becomes more and more difficult to occupy due to the repulsive force between the solute molecules. The results showed that the rate of $\mathrm{Mg}$ (II) adsorption was fast. This phenomenon was related to the mass transfer driving force. It should be due to the electrostatic attraction between TF-TY and $\mathrm{Mg}(\mathrm{II})$ ions.

\subsection{Kinetic analysis}

In order to understand the kinetics of $\mathrm{Mg}$ (II) adsorption on TF-TY, four models including pseudo first order rate equation (PFORE) (Lagergren, 1898), pseudo second order rate equation (PSORE) (Ho and McKay, 1999), Weber and Morris model (W\&M) (Weber and Morris, 1963) and Elovich model (Zeldowitsch, 1934) were used. These models equations are reported in Table 1.

Table 2 illustrated the sorption kinetics data of $\mathrm{Mg}(\mathrm{II})$ onto the studied TF-TY at normal sorption conditions. The pseudo-first-order and pseudo-second-order models were used to represent single-nuclear and dual-nuclear adsorption processes in solid solution systems, respectively (Chen et al., 2018). The linear form of pseudo-first-order equation is expressed in the form:

$$
\ln \left(q_{e}-q_{t}\right)=\ln q_{e}-k_{1} t
$$

where $\mathrm{q}_{\mathrm{e}}$ is the equilibrium adsorption capacity $\left(\mathrm{mg} \mathrm{g}^{-1}\right), \mathrm{k}_{1}$ is the pseudo-first-order kinetic rate constant, $\mathrm{t}$ is the adsorption time $(\mathrm{min})$ and $\mathrm{q}_{\mathrm{t}}$ is the adsorption capacity at t time $\left(\mathrm{mg} \mathrm{g}^{-1}\right)$. 
Table 1: Kinetics models

\begin{tabular}{lll}
\hline Kinetic model & Equation & References \\
\hline Pseudo-First order & $\mathrm{q}_{\mathrm{t}}=\mathrm{q}_{\mathrm{e}}\left[1-\mathrm{e}^{-\mathrm{k}_{1} \mathrm{t}}\right]$ & (Lagergren, 1898) \\
\hline Pseudo-Second order & $\mathrm{q}_{\mathrm{t}}=\frac{\mathrm{k}_{2} \mathrm{t}}{1+\mathrm{k}_{2} \mathrm{q}_{\mathrm{e}} \mathrm{t}}$ & (Ho and McKay, 1999) \\
\hline Intraparticle diffusion & $\mathrm{q}_{\mathrm{t}}=\mathrm{k}_{\mathrm{i}} \mathrm{t}^{0.5}+\mathrm{X}$ & (Weber and Morris, 1963) \\
\hline Elovich equation & $\frac{\mathrm{dq}}{\mathrm{dt}}=\alpha \mathrm{e}^{-\beta \mathrm{q}}$ & (Zeldowitsch, 1934) \\
\hline
\end{tabular}

$\mathrm{q}_{\mathrm{t}}\left(\mathrm{mg} \mathrm{g}^{-1}\right)$ : amount of dye sorbed at time $(\mathrm{t})$.

$\mathrm{q}_{\mathrm{e}}\left(\mathrm{mg} \mathrm{g}^{-1}\right)$ : equilibrium sorption.

$\mathrm{K}_{1}\left(\mathrm{~L} \mathrm{mg}^{-1}\right)$ : pseudo first -order rate constant of adsorption.

$\mathrm{K}_{2}\left(\mathrm{~g} \mathrm{mg}^{-1} \mathrm{~min}^{-1}\right)$ : pseudo second-order rate constant of adsorption.

$\mathrm{K}_{\mathrm{i}}\left(\mathrm{mg} \mathrm{g}^{-1} \min ^{-0.5}\right)$ : the intra-particle diffusion rate.

$\mathrm{X}\left(\mathrm{mg} \mathrm{g}^{-1}\right)$ :the boundary layer diffusion effects (external film resistance)

$\alpha\left(\mathrm{mg} \mathrm{g}^{-1} \mathrm{~min}^{-1}\right)$ : the initial sorption rate.

$\beta\left(\mathrm{g} \mathrm{mg}^{-1}\right)$ : the desorption constant.

The pseudo-first-order kinetic equation was obtained by drawing the linear plots of $\ln \left(\mathrm{q}_{\mathrm{e}}-\mathrm{q}_{\mathrm{t}}\right)$ versus $\mathrm{t}$ (Fig. 6 (a)). the corresponding parameters were listed in Table 2. It could obtain from Table 2 that the correlation coefficient value of pseudo-first-order obtained was relatively small. This indicated that the adsorption of $\mathrm{Mg}(\mathrm{II})$ ions onto the TF-TY is not belong to pseudo-first-order equation. The pseudo-second-order dynamic equations can be expressed in the following form:

$$
\frac{t}{q_{t}}=\frac{1}{k_{2} q_{e}^{2}}+\left(\frac{1}{q_{e}}\right) t
$$

where $\mathrm{k}_{2}\left(\mathrm{~g} \mathrm{mg}^{-1} \mathrm{~min}^{-1}\right)$ is the rate constant of the pseudo-second-order reaction, and can be obtained through the slope and intercept of plot $t / \mathrm{q}_{\mathrm{t}}$ against $\mathrm{t}$ (Fig. 6 (b)). It could be seen from Fig. 6 (a) (b) that the pseudo-first-order kinetic adsorption data slightly deviated from the fitting curve, and the correlation coefficient $\mathrm{R}^{2}$ was 0.9428 . The fitting effect of the pseudosecond-order kinetic equation was relatively good, and the adsorption data was basically consistent with the fitting curve. $\mathrm{R}^{2}$ was 0.9993 . This phenomenon indicated that the adsorption mechanism of TF-TY to MB solution was diverse but it was still based on chemistry (Smith et al., 2016). The pseudo-second-order kinetic model provides a better fit than the pseudo-first-order model, suggesting that $\mathrm{Mg}(\mathrm{II})$ adsorption to TF-TY might involve multi-nucleus rather than single-nucleus adsorption process. Similar phenomena were reported for $\mathrm{As}(\mathrm{V})$ adsorption onto poly $\mathrm{p}$-phenylenediamine- thiourea-formaldehyde polymer (Elwakeel and Al-Bogami, 2018).

The intraparticle diffusion model provides a more comprehensive approach for defining of sorption mechanism, and the plot generally allows identifying different successive steps in the global process (Markovski et al., 2014). 
Table 2: Kinetic parameters for $\mathrm{Mg}(\mathrm{II})$ adsorption

\begin{tabular}{|c|c|c|c|c|c|c|c|c|c|c|c|}
\hline \multicolumn{3}{|c|}{$\begin{array}{c}\text { Pseudo-First order rate } \\
\text { equation }\end{array}$} & \multicolumn{3}{|c|}{ Pseudo-Second order rate equation } & \multicolumn{3}{|c|}{ Weber and Morris model } & \multicolumn{3}{|c|}{ Elovich equation } \\
\hline $\begin{array}{l}\mathrm{k}_{1} \\
\text { (a) }\end{array}$ & $\begin{array}{c}\mathrm{q}_{\mathrm{e}, \mathrm{calc}} \\
\text { (b) }\end{array}$ & $\mathrm{R}^{2}$ & $\begin{array}{l}\mathrm{k}_{2} \\
\text { (c) }\end{array}$ & $\begin{array}{c}\mathrm{q}_{\mathrm{e}, \text { calc }} \\
\text { (b) }\end{array}$ & $\mathrm{R}^{2}$ & $\begin{array}{l}\mathrm{ki} \\
\text { (d) }\end{array}$ & $X$ & $\mathrm{R}^{2}$ & $\begin{array}{c}\alpha \\
(\mathrm{e})\end{array}$ & $\begin{array}{l}\beta \\
\text { (f) }\end{array}$ & $\mathrm{R}^{2}$ \\
\hline \multirow{3}{*}{0.011} & \multirow{3}{*}{10.735} & \multirow{3}{*}{0.9428} & \multirow{3}{*}{0.0017} & \multirow{3}{*}{18.78} & \multirow{3}{*}{0.9993} & 1.371 & 1.487 & 0.9686 & \multirow{3}{*}{1.66} & \multirow{3}{*}{0.28} & \multirow{3}{*}{0.9667} \\
\hline & & & & & & 0.349 & 11.256 & 0.9399 & & & \\
\hline & & & & & & 0.184 & 13.795 & 0.9941 & & & \\
\hline
\end{tabular}

Units: (a): $\min ^{-1}$; (b): $\mathrm{mg} \mathrm{g}^{-1}$; (c): $\mathrm{g} \mathrm{mg}^{-1} \min ^{-1} ;(\mathrm{d}): \mathrm{mg} \mathrm{g}^{-1} \min ^{0.5} ;(\mathrm{e}): \mathrm{mg} \mathrm{g}^{-1} \min ^{-1}$; (f): $\mathrm{g} \mathrm{mg}^{-1}$.
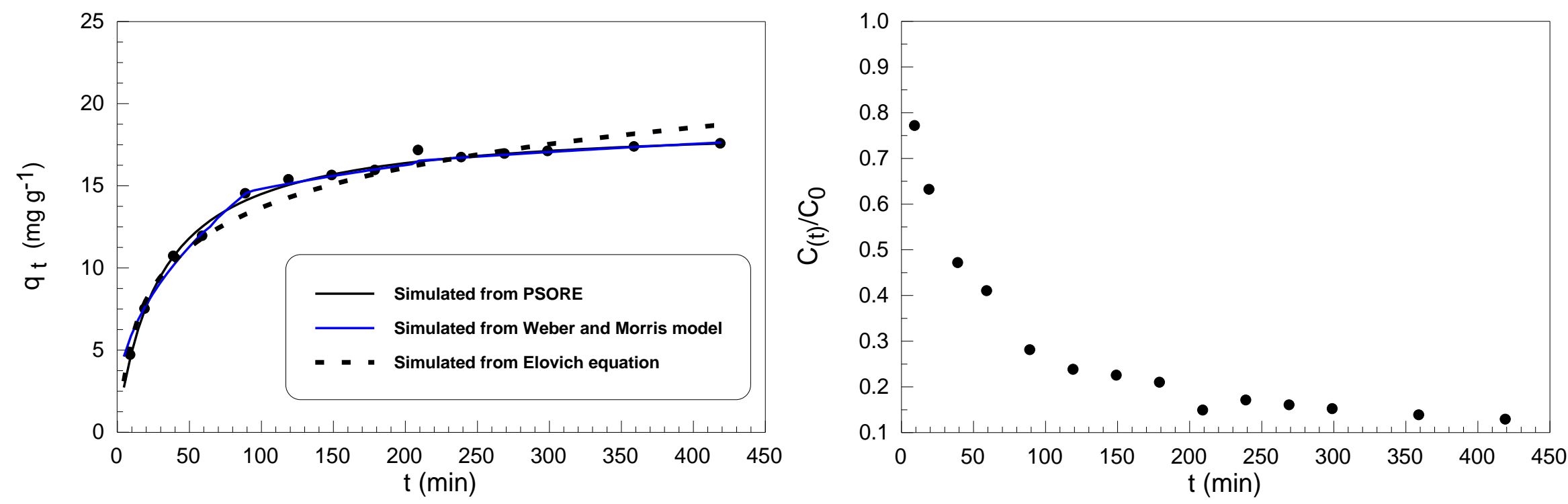

Fig. 5. The variation of adsorption capacity with adsorption time: (a) at $20 \mathrm{mg} \mathrm{L}^{-1}$ initial $\mathrm{Mg}$ (II) concentrations (T:298 K; m:0.05 g; V:20 mL). 

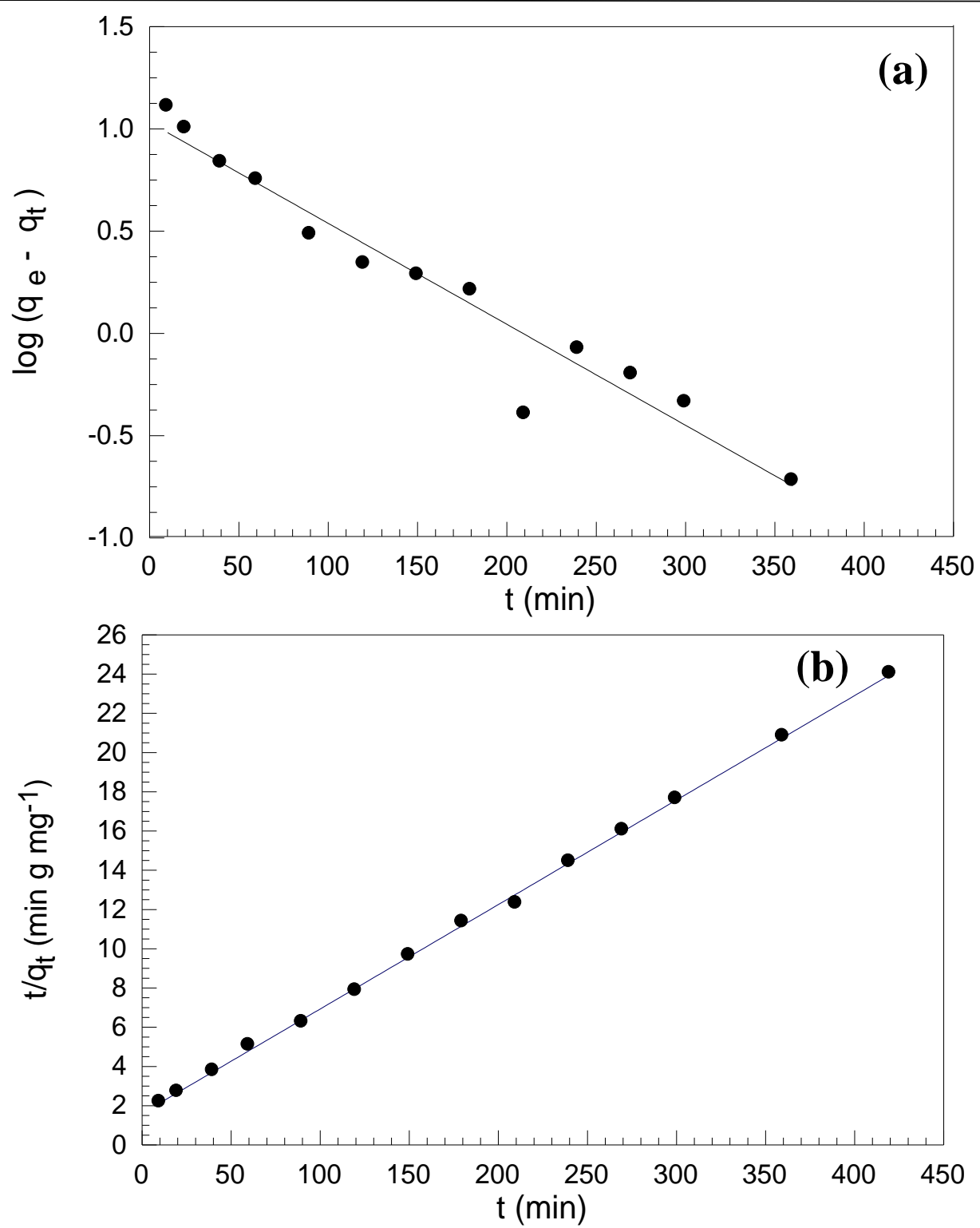

Fig. 6. (a) Pseudo-first-order kinetics and (b) Pseudo-second-order kinetics of $\mathrm{Mg}$ (II) ions onto TF-TY sorbent at $298 \mathrm{~K}$ (T:298 K; m:0.05 g; V:20 mL).

The Weber and Morris shows multi-linear sections (Fig. 7(a)), i.e., three linear sections (on the plot $\mathrm{q}_{\mathrm{t}} v s . \mathrm{t}^{0.5}$ ) with fast kinetics in first step followed by the gradual attainment of equilibrium, and a pseudo saturation plateau. The multi-linear plot does not pass through the origin suggesting that the resistance to intraparticle diffusion is not the sole rate-limiting step: other steps, e.g. resistance to film diffusion and/or reaction rate, are probably involved in the control of uptake kinetics (Table 2). The second section is characterized by a much lower kinetic rate and leads to a slow approach to equilibrium with the control by the resistance to intraparticle diffusion (into internal macroporous and mesoporous network). From the second region of the plot, which intraparticle diffusion related micro-pore diffusion is occurred; $\mathrm{Ki}_{2}, \mathrm{X}$ and $\mathrm{R}^{2}$ values were calculated and given in Table 2. A significant difference of $\mathrm{K}_{\mathrm{i}}$ values (Table 2) indicate the availability of the functional groups is primary controlled by diffusional transport through pores system in second and third steps, structure of the porous sorbent, i.e. pores network, consists from 
macropores which extends into particle interior and branched into tree like system of meso and micropores. The $\mathrm{Mg}$ (II) ions must diffuse through whole pore systems to reach total surface area within the particles, where the intra-particle diffusion, resistance due to diffusional transport inside pores, slow down overall process contributing to formation of time-dependent concentration gradient due to fast kinetic process at surface, until saturation of all available surface sites was achieved. $X$ represents the boundary layer diffusion effects (external film resistance). As the value of $\mathrm{X}$ decreases the effect of boundary layer diffusion on the reaction rate decreases. The obtained values of $\mathrm{X}$ (Table2) indicate that the boundary layer diffusion effect (external film resistance) has significant effect on the diffusion rate. The last step is very slow and represents only a few percentage of the total sorption: this phase can be associated to the resistance to diffusion in the microporous network of the sorbent. In addition, the progressive saturation of available and accessible sorption sites influences the local equilibrium on the surface between surface sorption and desorption.

Elovich's equation is another rate equation based on the sorption capacity. In 1934 the kinetic law of chemisorptions was established though the work of Zeldowitsch (Zeldowitsch, 1934). It has commonly been called the Elovich equation. The values of $\alpha$ and $\beta$ were determined from the intercept and slope, respectively, of the linear plot of $q_{t}$ vs lnt (Fig. 7(b)). The value of $\alpha$ for the sorption of $\mathrm{Mg}$ (II) ions on the TF-TY sorbent is $1.66\left(\mathrm{mg} \mathrm{g}^{-1} \mathrm{~min}^{-1}\right)$. This value indicate that the initial sorption rate of $\mathrm{Mg}$ (II) ions is relatively high compared with the previous studies of Aikpokpodion Paul et al (Aikpokpodion Paul et al., 2013). The high initial sorption rate of $\mathrm{Mg}$ (II) onto TF-TY sorbent may be attributed to the high concentration of active sites on the sorbent surface allowed for reacting with $\mathrm{Mg}$ (II) ions. The value of $\beta$ (desorption constant) is found to be $0.28 \mathrm{~g} \mathrm{mg}^{-1}$.

Table 3 summarizes $\mathrm{Mg}$ (II) sorption properties for a series of alternative sorbents. Some sorbents have outstanding sorption capacities at saturation. However, the equilibrium time allow ranking TF-TY sorbent among the most efficient sorbents.

Table 3. $\mathrm{Mg}(\mathrm{II})$ sorption performances of selected sorbents.

\begin{tabular}{|l|l|l|l|}
\hline Adsorbent & Equilibrium time (min) & $\begin{array}{l}\text { Maximum adsorption } \\
\text { capacity }\left(\mathbf{m g ~ g}^{-1}\right)\end{array}$ & Ref. \\
\hline $\begin{array}{l}\text { Bentonite/c-alumina } \\
\text { nanocomposite }\end{array}$ & 60 & 3.478 & $\begin{array}{l}\text { (Pourshadlou et al., } \\
\text { 2020) }\end{array}$ \\
\hline Bentonite (natural) & 20 & 26.24 & $\begin{array}{l}\text { (Shahmirzadi et al., } \\
\text { 2016) }\end{array}$ \\
\hline Calcined bentonite & 20 & 35.67 & $\begin{array}{l}\text { (Shahmirzadi et al., } \\
\text { 2016) }\end{array}$ \\
\hline $\begin{array}{l}\text { Microwave radiated } \\
\text { zeolite }\end{array}$ & - & 31.23 & $\begin{array}{l}\text { (Shahmirzadi et al., } \\
\text { 2016) }\end{array}$ \\
\hline Natural pumice & 240 & 44.53 & (Sepehr et al., 2013) \\
\hline Modified pumice & 240 & 56.11 & (Sepehr et al., 2013) \\
\hline Mercerized cellulose & 50 & 21.7 & (Karnitz et al., 2010) \\
\hline $\begin{array}{l}\text { mercerized sugarcane } \\
\text { bagasse grafted with } \\
\text { EDTA dianhydride }\end{array}$ & 50 & 42.6 & (Karnitz et al., 2010) \\
\hline TF-TY & 120 & & Present study \\
\hline
\end{tabular}



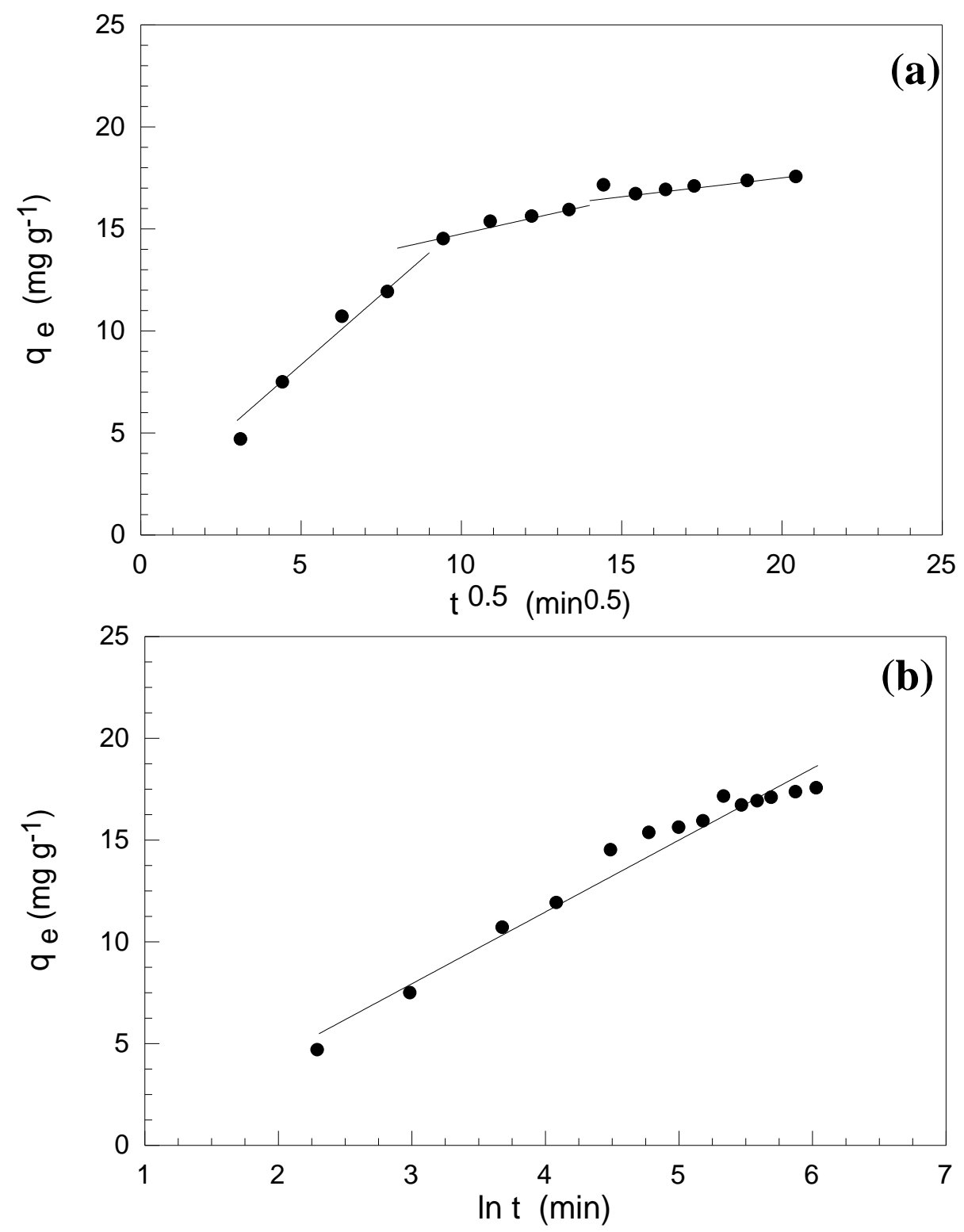

Fig. 7. (a) intraparticle diffusion model and (b) Elovich equation for adsorption of $\mathrm{Mg}(\mathrm{II})$ ions onto TF-TY sorbent at $298 \mathrm{~K}\left(\mathrm{C}_{0} ; 20 \mathrm{mg} \mathrm{L}^{-1} ; \mathrm{pH}_{0} ; 10.5\right)$.

\section{4- CONCLUSIONS}

The research shows that the TF-TY could be used to remove $\mathrm{Mg}$ (II) ions as cheap and available adsorbent. It was observed that the $\mathrm{pH}$ dependency of adsorption of $\mathrm{Mg}$ (II) was large. The amount of $\mathrm{Mg}$ (II) uptake increased with increasing of contact time. Their maximum adsorption capacity was $19.45 \mathrm{mg} \mathrm{g}^{-1}$. The adsorption kinetics was consistent with the pseudo-second-order kinetics models. It could be found that TF-TY has the good adsorption effect on $\mathrm{Mg}$ (II) ions, indicating that TF-TY could be used as the best an available material for water hardness reduction. 


\section{5- CONFLiCT OF INTEREST}

The authors declare that they have no known competing financial interests or personal relationships that could have influenced the work reported in this paper.

\section{6- REFERENCES}

Abukhadra, M.R., Adlii, A., El-Sherbeeny, A.M., Ahmed Soliman, A.T. and Abd Elgawad, A.E.E. 2020. Promoting the decontamination of different types of water pollutants $(\mathrm{Cd} 2+$, safranin dye, and phosphate) using a novel structure of exfoliated bentonite admixed with cellulose nanofiber. J. Environ. Manage. 273, 111130.

Aikpokpodion Paul, E., Osobamiro, T., Atewolara-Odule, O. and Oduwole, O. 2013. Studies on adsorption mechanism and kinetics of magnesium in selected cocoa growing soils in Nigeria. J. chem. pharm. Res. 5(6), 128-139.

Alaei Shahmirzadi, M.A., Hosseini, S.S., Luo, J. and Ortiz, I. 2018. Significance, evolution and recent advances in adsorption technology, materials and processes for desalination, water softening and salt removal. J. Environ. Manage. 215, 324-344.

Avci, H., Dokuz, U.E. and Avci, A.S. 2018. Hydrochemistry and groundwater quality in a semiarid calcareous area: an evaluation of major ion chemistry using a stoichiometric approach. Environ. Monit. Assess. 190(11), 641.

Burn, S., Hoang, M., Zarzo, D., Olewniak, F., Campos, E., Bolto, B. and Barron, O. 2015. Desalination techniques - A review of the opportunities for desalination in agriculture. Desalination 364, 2-16.

Chen, Y.-d., Lin, Y.-C., Ho, S.-H., Zhou, Y. and Ren, N.-q. 2018. Highly efficient adsorption of dyes by biochar derived from pigments-extracted macroalgae pyrolyzed at different temperature. Bioresour. Technol. 259, 104-110.

Comstock, S.E. and Boyer, T.H. 2014. Combined magnetic ion exchange and cation exchange for removal of DOC and hardness. Chem. Eng. J. 241, 366-375.

El-Nahas, S., Osman, A.I., Arafat, A.S., Al-Muhtaseb, A.a.H. and Salman, H.M. 2020. Facile and affordable synthetic route of nano powder zeolite and its application in fast softening of water hardness. J. Water Process. Eng. 33, 101104.

Elwakeel, K.Z. and Al-Bogami, A.S. 2018. Influence of Mo(VI) immobilization and temperature on $\mathrm{As}(\mathrm{V})$ sorption onto magnetic separable poly p-phenylenediaminethiourea-formaldehyde polymer. J. Hazard. Mater. 342, 335-346.

Elwakeel, K.Z., Elgarahy, A.M., Khan, Z.A., Almughamisi, M.S. and Al-Bogami, A.S. 2020a. Perspectives regarding metal/mineral-incorporating materials for water purification: with special focus on $\mathrm{Cr}$ (vi) removal. Mater. Adv. 1(6), 1546-1574.

Elwakeel, K.Z., Shahat, A., Khan, Z.A., Alshitari, W. and Guibal, E. 2020b. Magnetic metal oxide-organic framework material for ultrasonic-assisted sorption of titan yellow and rose bengal from aqueous solutions. Chem. Eng. J. 392, 123635.

Hailu, Y., Tilahun, E., Brhane, A., Resky, H. and Sahu, O. 2019. Ion exchanges process for calcium, magnesium and total hardness from ground water with natural zeolite. Groundw. Sustain. Dev. 8, 457-467. 
Harper, C. and Snowden, M. (2017) Environment and society: Human perspectives on environmental issues, Taylor \& Francis.

Ho, Y.S. and McKay, G. 1999. Pseudo-second order model for sorption processes. Process Biochem. 34(5), 451-465.

Karnitz, O., Gurgel, L.V.A. and Gil, L.F. 2010. Removal of $\mathrm{Ca}(\mathrm{II})$ and $\mathrm{Mg}$ (II) from aqueous single metal solutions by mercerized cellulose and mercerized sugarcane bagasse grafted with EDTA dianhydride (EDTAD). Carbohydr. Polym. 79(1), 184-191.

Lagergren, S.K. 1898. About the theory of so-called adsorption of soluble substances. Sven. Vetenskapsakad. Handingarl 24, 1-39.

Markovski, J.S., Marković, D.D., Đokić, V.R., Mitrić, M., Ristić, M.Đ., Onjia, A.E. and Marinković, A.D. 2014. Arsenate adsorption on waste eggshell modified by goethite, $\alpha-$ MnO2 and goethite/ $\alpha-M n O 2$. Chem. Eng. J. 237, 430-442.

Ndii, M.Z., Tambaru, D. and Djahi, B.S. 2020 The effects of hard water consumption on kidneyrelated diseases, p. 020009, AIP Publishing LLC.

Ojha, P. 2020. Engineering Chemistry Chapter-1 Water.

Patil, V.B., Pinto, S.M., Govindaraju, T., Hebbalu, V.S., Bhat, V. and Kannanur, L.N. 2020. Multivariate statistics and water quality index (WQI) approach for geochemical assessment of groundwater quality - a case study of Kanavi Halla Sub-Basin, Belagavi, India. Environ. Geochem. Health 42(9), 2667-2684.

Pilehvar, A., Cordery, K.I., Town, R.M. and Blust, R. 2020. The synergistic toxicity of Cd(II) and $\mathrm{Cu}(\mathrm{II})$ to zebrafish (Danio rerio): Effect of water hardness. Chemosphere 247, 125942.

Pourshadlou, S., Mobasherpour, I., Majidian, H., Salahi, E., Shirani Bidabadi, F., Mei, C.-T. and Ebrahimi, M. 2020. Adsorption system for Mg2+ removal from aqueous solutions using bentonite/ $\gamma$-alumina nanocomposite. J. Colloid Interface Sci. 568, 245-254.

Saleh, I.A., Zouari, N. and Al-Ghouti, M.A. 2020. Removal of pesticides from water and wastewater: Chemical, physical and biological treatment approaches. Environ. Technol. Innov., 101026.

Sepehr, M.N., Zarrabi, M., Kazemian, H., Amrane, A., Yaghmaian, K. and Ghaffari, H.R. 2013. Removal of hardness agents, calcium and magnesium, by natural and alkaline modified pumice stones in single and binary systems. Appl. Surf. Sci. 274, 295-305.

Shahmirzadi, M.A.A., Hosseini, S.S. and Tan, N.R. 2016. Enhancing removal and recovery of magnesium from aqueous solutions by using modified zeolite and bentonite and process optimization. Korean J. Chem. Eng. 33(12), 3529-3540.

Smith, Y.R., Bhattacharyya, D., Willhard, T. and Misra, M. 2016. Adsorption of aqueous rare earth elements using carbon black derived from recycled tires. Chem. Eng. J. 296, 102111.

Weber, W.J. and Morris, J.C. 1963. Kinetics of adsorption on carbon from solution. J. Sanit. Eng. Div. 89(2), 31-60.

Xu, H., Xu, Z., Guo, Y., Guo, S., Xu, X., Gao, X., Wang, L. and Yan, W. 2020. Research and application progress of electrochemical water quality stabilization technology for recirculating cooling water in China: A short review. J. Water Process. Eng. 37, 101433. 
Aswan University Journal of Environmental Studies (AUJES) 1 (2), pp. 125-136, (2020).

Online ISSN: 2735-4237, Print: ISSN 2735-4229. https://aujes.journals.ekb.eg/

Zeldowitsch, J. 1934. The catalytic oxidation of carbon monoxide on manganese dioxide. Acta Physicochim. URSS 1, 364-449. 